\title{
FAKTOR-FAKTOR YANG MEMPENGARUHI PRODUKSI USAHATANI KOPI ARABIKA DI KABUPATEN ENREKANG SULAWESI SELATAN
}

\section{FACTORS AFFECTING THE PRODUCTION OF ARABICA COFFEE FARMING AT ENRENKANG SOUTH SULAWESI}

\author{
Syahruni Thamrin ${ }^{1}$
}

Diterima 22 September 2014, disetujui 31 Oktober 2014

\begin{abstract}
This study aims to identify and analyze the factors that affect the production of Arabica coffee in Enrekang. This study used survey method to conduct interviews with 100 randomly sampled Arabica coffee farmers and site visit to their farms. Factors affecting farm production were analyzed using the Cobb Douglass production function and estimated using least squares method. There were ten coffee production factors assessed: land size, number of productive plants, quantities of Urea, ZA, SP36, KCl, pesticides, herbicides, manure, as well as labor force. Variables that significantly affect Arabica coffee production in Enrekang are the amount of urea, ZA, herbicides, manure, and labor.
\end{abstract}

Keywords: Arabica coffee, production factors, Cobb-Douglas production function, Enrekang

\section{PENDAHULUAN}

Kopi merupakan salah satu komoditas perkebunan yang mempunyai peran penting dalam kegiatan perekonomian di Indonesia. Hal ini karena kopi telah memberikan sumbangan yang cukup besar bagi devisa negara, menjadi ekspor non migas, selain itu dapat menjadi penyedia lapangan kerja dan sumber pendapatan bagi petani pekebun kopi maupun bagi pelaku ekonomi lainnya yang terlibat dalam budidaya, pengolahan, maupun dalam mata rantai pemasaran.

Selama lima tahun terakhir, Indonesia menempati posisi keempat sebagai negara eksportir kopi setelah Brazil, Kolombia dan Vietnam. Indonesia juga merupakan negara penghasil kopi robusta terbesar kedua di dunia setelah Vietnam (ICO,
2010). Di sisi lain, meskipun kontribusi kopi Arabika Indonesia dalam perdagangan kopi dunia secara kuantitatif sangat kecil, namun secara kualitatif sangat disukai konsumen dengan keanekaragaman jenis serta cita rasanya yang spesifik.

Sulawesi Selatan merupakan salah satu propinsi di Kawasan Timur Indonesia yang memiliki potensi pengembangan kopi. Hal ini ditunjukkan dengan areal penanaman yang cukup luas serta keadaan agroklimatologi yang sangat mendukung. Berdasarkan data Dinas Perkebunan Sulawesi Selatan (2005), volume ekspor kopi arabika asal Sulawesi Selatan periode 2009 tercatat 4,11 juta ton dengan nilai ekspor sebanyak 14,45 juta dolar AS. Dari total volume ekspor kopi arabika tersebut, terbanyak dikirim ke AS yakni 1,9 juta ton, kemudian Jepang 628.037 ton, dan Belgia 379.200

${ }^{1}$ Jurusan Budidaya Tanaman Perkebunan, Politeknik Pertanian Negeri Pangkep, Sulawesi Selatan, syahrunithamrin@gmail.com 
ton. Sementara ekspor kopi ke Italia hanya 36.000 ton dengan nilai ekspor 113.400 dolar AS.

Berikut ini adalah data perkembangan luas areal, jumlah produksi dan jumlah KK yang berusahatani kopi arabika di Kabupaten Enrekang, disajikan pada Tabel 1.

\section{METODE PENELITIAN}

\section{Penentuan Lokasi dan Pengambilan Sampel}

Penelitian dilaksanakan di Kabupaten Enrekang, dengan pertimbangan merupakan sentra produksi kopi Arabika di Provinsi Sulawesi Selatan. Di Kabupaten Enrekang ada 5 (lima) kecamatan yang

Tabel 1. Luas Areal, Jumlah Produksi dan Jumlah KK Komoditi Kopi Arabika di Kabupaten Enrekang Tahun 2005 dan 2011

\begin{tabular}{|c|c|c|c|c|c|c|}
\hline \multirow{2}{*}{ Tahun } & \multicolumn{4}{|c|}{ Luas Areal (ha) } & \multirow{2}{*}{$\begin{array}{l}\text { Produksi } \\
\text { (ton/tahun) }\end{array}$} & \multirow{2}{*}{$\begin{array}{c}\text { Jumlah Petani } \\
\text { (KK) }\end{array}$} \\
\hline & TBM & TM & $\mathrm{TR} / \mathrm{TT}$ & Jumlah & & \\
\hline 2006 & 1.246 & 7.254 & 2.331 & 10.833 & $6.413,00$ & 14.837 \\
\hline 2011 & 1.132 & 8.409 & 2.408 & 11.949 & $7.932,74$ & 17.521 \\
\hline
\end{tabular}

Sumber: Dinas Kehutanan dan Perkebunan Kabupaten Enrekang (2005)

Dinas Perkebunan Kabupaten Enrekang (2011)

Keterangan: $\mathrm{TBM}=$ tanaman belum menghasilkan

$\mathrm{TM}=$ tanaman menghasilkan

$\mathrm{TR}=$ tanaman yang direhabilitasi

$\mathrm{TT}=$ tanaman yang sudah tua

$\mathrm{KK}=$ kepala keluarga

Dari Tabel 1 terlihat bahwa baik luas areal penanaman, produksi maupun jumlah petani yang mengusahakan kopi arabika terus mengalami peningkatan. Hal ini disebabkan potensi pasar kopi global khusus terbuka luas. Namun disisi lain, petani kopi di Kabupaten Enrekang masih memiliki kendala dalam mengembangkan usahataninya, misalnya dalam hal kendala teknis dimana pengelolaan usahataninya masih bersifat tradisional alokasi input produksi belum optimal dan perkembangan harga cukup berfluktuasi karena mengikuti pasar kopi dunia, dan manajemen yang dihadapi petani untuk memenuhi standar perusahaan dan pasar internasional.

Berdasarkan teori produksi dalam kaitannya dengan pertanian, faktor yang penting dalam pengelolaan sumberdaya produksi adalah faktor alam (tanah), modal, tenaga kerja, dan juga manajemen. Untuk itulah dilakukan penelitian ini untuk mengetahui faktor-faktor yang mempengaruhi produksi pada usahatani kopi arabika. menjadi sentra pengembangan, yaitu Kecamatan Bungin, Buntubatu, Masalle, Baraka dan Baroko. Lokasi penelitian ditentukan secara purposive sampling, dan lokasi yang dipilih yaitu Kecamatan Baroko, dan selanjutnya dipilih 2 (dua) desa, yaitu Desa Baroko dan Desa Benteng Alla.

Teknik pengumpulan data dilakukan dengan teknik observasi dan wawancara. Kriteria petani sampel adalah rumah tangga petani yang melaksanakan usahatani kopi arabika. Penentuan sampel dilakukan dengan cara random sampling. Jumlah sampel yang diambil sebanyak 100 sampel petani dan terdistribusi secara merata pada kedua desa tersebut.

\section{Metode Analisis}

Fungsi produksi yang digunakan dalam penelitian ini adalah fungsi produksi stochastic frontier Cobb-Douglass. Bentuk ini dipilih karena sederhana dan dapat meminimumkan terjadinya multikolinearitas. Seperti yang dijelaskan Aigner 
et al. (1977) dan Meeusen dan Broeck (1997), diacu dalam Coelli et al. (1998) persamaan fungsi produksi yang dispesifikasi untuk data silang (crosssectional data) yang mempunyai dua komponen error term, yaitu vi dan ui.

Model regresi pengaruh penggunaan input terhadap produksi pada usahatani kopi arabika secara umum adalah:

$$
\begin{aligned}
& \operatorname{Ln} \mathrm{y}=\ln \alpha_{0}+\alpha_{1} \ln \mathrm{x}_{1}+\alpha_{2} \ln \mathrm{x}_{2}+\alpha_{3} \ln \mathrm{x}_{3}+\alpha_{4} \ln \mathrm{x}_{4}+\alpha_{5} \\
& \ln x_{5}+\alpha_{6} \ln x_{6}+\alpha_{7} \ln x_{7}+\alpha_{8} \ln x_{8}+\alpha_{9} \ln x_{9}+ \\
& \alpha_{10} \ln x_{10}+\varepsilon_{1}
\end{aligned}
$$

Keterangan:

y : produktivitas kopi arabika per luas lahan $(\mathrm{kg} / \mathrm{ha})$

$\mathrm{x}_{1}$ : luas lahan (ha)

$\mathrm{x}_{2:}$ : jumlah pohon produktif (jumlah pohon/ha)

$\mathrm{x}_{3}$ : pupuk Urea per luas lahan $(\mathrm{kg} / \mathrm{ha})$

$\mathrm{x}_{4}$ : pupuk ZA per luas lahan $(\mathrm{kg} / \mathrm{ha})$

$\mathrm{x}_{5}$ : pupuk SP36 per luas lahan $(\mathrm{kg} / \mathrm{ha})$

$\mathrm{x}_{6}$ : pupuk $\mathrm{KCl}$ per luas lahan $(\mathrm{kg} / \mathrm{ha})$

$\mathrm{x}_{7}$ : pestisida per luas lahan (ltr/ha)

$\mathrm{x}_{8}$ : herbisida per luas lahan (ltr/ha)

$\mathrm{x}_{9}$ : pupuk kandang $(\mathrm{kg} / \mathrm{ha})$

$\mathrm{x}_{10}$ : tenaga kerja per luas lahan $(\mathrm{HOK} / \mathrm{ha})$

$\alpha_{0}:$ intersep

$\alpha_{i}$ : koefisien parameter penduga, di mana $i=1,2,3, \ldots, 10$

$\varepsilon_{1}^{2}$ : risiko produksi (residual)

$0<\beta \mathrm{i}<1$ (diminishing return)

\section{HASIL DAN PEMBAHASAN}

Pemilihan input atau faktor-faktor produksi dalam usahatani kopi arabika perlu dilakukan, karena dengan pemilihan input atau faktor produksi yang tepat atau tidak tepat akan berpengaruh pada tinggi rendahnya produksi kopi yang didapat.

Penelitian ini menggunakan sepuluh faktor produksi, antara lain: luas lahan, jumlah pohon produktif, pupuk Urea, ZA, SP36, KCl, pestisida, herbisida, pupuk kandang, dan tenaga kerja. Analisis faktor-faktor yang mempengaruhi produksi dengan menggunakan fungsi produksi Cobb-Douglas, data yang dianalisis dalam bentuk Ln. Hasil analisis fungsi Cobb-Douglas dapat dilihat pada Tabel 2.

Berdasarkan hasil analisis yang tersaji pada tabel 2 diketahui bahwa nilai koefisien determinasi $\left(\mathrm{R}^{2}\right)$ sebesar 0,953 . Hal ini berarti sebanyak 95,3 persen variasi dari produksi kopi arabika dapat dijelaskan oleh variasi variabel independen dalam model, dengan kata lain 95,3 persen variabel independen secara bersama-

Tabel 2. Faktor-faktor yang mempengaruhi Produksi Kopi Arabika di Kabupaten Enrekang

\begin{tabular}{lccccc}
\hline \multicolumn{1}{c}{ Variabel } & T.Harapan & Koefisien & Std Eror & t-hitung & Prob \\
\hline C & + & $3.434^{* * *}$ & 0.453 & 7.582 & 0.000 \\
Luas Lahan & + & $0.011^{\mathrm{ns}}$ & 0.057 & 0.191 & 0.849 \\
Jml T. produktif & + & $-0.016^{\mathrm{ns}}$ & 0.056 & -0.291 & 0.772 \\
Pupuk Urea & + & $0.199^{* * *}$ & 0.073 & 2.720 & 0.008 \\
Pupuk ZA & + & $0.183^{* * *}$ & 0.035 & 5.162 & 0.000 \\
Pupuk SP36 & + & $0.082^{\mathrm{ns}}$ & 0.053 & 1.543 & 0.126 \\
Pupuk KCl & + & $0.014^{\mathrm{ns}}$ & 0.066 & 0.217 & 0.829 \\
Pestisida & + & $0.007^{\mathrm{ns}}$ & 0.051 & 0.146 & 0.885 \\
Herbisida & + & $0.086^{* *}$ & 0.039 & 2.189 & 0.031 \\
Pupuk kandang & + & $0.062^{*}$ & 0.033 & 1.865 & 0.066 \\
Tenaga kerja & + & $0.313^{* * *}$ & 0.092 & 3.385 & 0.001 \\
\hline R-squared & 0,953 & $\left.{ }^{* * *}\right)=$ Signifikan pada tingkat kesalahan $1 \%$ \\
Adjusted R-squared & 0,948 & ${ }^{* * *}$ = Signifikan pada tingkat kesalahan $5 \%$ \\
F-statistic & 179,78 & $\left.{ }^{*}\right)=$ Signifikan pada tingkat kesalahan $10 \%$ \\
\multicolumn{7}{r}{ ns = tidak signifikan } \\
\hline
\end{tabular}

Sumber: Analisis Data Primer (2012) 
sama berpengaruh terhadap produksi dan sisanya 4,7 persen dipengaruhi oleh hal lain yang tidak diteliti. Hasil uji menunjukkan bahwa nilai $\mathrm{F}$ hitung ( $\alpha=1 \%$ ) sebesar 179,78 lebih besar dari F tabel (2,61), berarti bahwa variabel independen secara bersama-sama berpengaruh nyata terhadap produksi kopi arabika.

Hasil uji t menunjukkan bahwa koefisien regresi yang bertanda positif dan variabel yang berpengaruh nyata terhadap produksi per luas lahan kopi arabika adalah pupuk Urea, pupuk ZA, herbisida, pupuk kandang dan tenaga kerja.

Penggunaan pupuk urea berpengaruh positif dan nyata terhadap produktivitas kopi arabika. Penambahan pupuk Urea sebesar 1 persen akan meningkatkan produktivitas 0,199 persen, ceteris paribus. Artinya peningkatan penggunaan pupuk Urea akan diikuti oleh peningkatan produksi sampai batas tertentu yang dibutuhkan oleh tanaman. Hal ini disebabkan karena unsur Nitrogen yang terdapat dalam pupuk Urea dibutuhkan oleh tanaman kopi arabika bagi pertumbuhan dan produksi kopi arabika. Hal ini sesuai dengan penelitian Salazar (2006) pada tanaman kopi rakyat dan ditemukan bahwa semua input yang digunakan memberikan kontribusi positif bagi produksi kopi.

Penggunaan pupuk ZA berpengaruh positif dan nyata terhadap produktivitas kopi arabika. Nilai elastisitas pupuk ZA adalah 0,183, ini berarti penambahan pupuk ZA sebesar 1 persen akan meningkatkan produktivitas kopi arabika sebesar 0,183 persen, ceteris paribus. Hal ini berarti semakin meningkat penggunaan pupuk ZA maka produktivitas kopi akan semakin meningkat pula. Hal tersebut dapat dilihat bahwa tanaman kopi arabika memerlukan pupukZA agar dapat tumbuh dan berproduksi optimal. Penambahan pupuk ZA berdampak signifikan terhadap produksi, hal ini disebabkan karena pupuk ZA mengandung 21 persen $\mathrm{N}$ dan 24 persen $\mathrm{S}$, dimana pada tanaman unsur Nitrogen berfungsi untuk pertumbuhan vegetatif (untuk memperbesar, mempertinggi, menghijaukan daun), juga berfungsi untuk menyusun klorofil dan pembentukan tunas, sedangkan unsur Sulfur(S) berfungsi mengikat nitrogen di udara pada proses produksi. Belerang (sulfur) dalam pupuk ZA sangat membantu perkembangan pucuk, akar dan buah, memperbaiki rasa dan warna hasil panen, memperbaiki aroma, mengurangi penyusutan selama penyimpanan, tanaman lebih sehat dan lebih tahan terhadap gangguan lingkungan (hama, penyakit, kekeringan), jadi semuanya berhubungan dengan peningkatan produktivitas. Pupuk ZA mempunyai sifat tidak menyerap banyak air selain itu daya serap tanaman akan lebih lama, sehingga hijau daun bertahan lebih lama bila dibandingkan urea, dan senyawa kimianya stabil sehingga tahan disimpan dalam waktu lama, hal ini yang menyebabkan petani menggunakan pupuk ZA ini.

Koefisien regresi variabel herbisida memiliki tanda positif dan berpengaruh nyata terhadap produktivitas kopi arabika. Hal ini berarti penambahan penggunaan herbisida 1 persen akan meningkatkan produktivitas sebesar 0,086 persen, ceteris paribus. Hal tersebut dapat dilihat dari kurangnya gulma yang tumbuh di sekitar pertanaman kopi sehingga tanaman kopi dapat tumbuh dan berproduksi dengan baik tanpa adanya gangguan gulma.

Berdasarkan tanda parameter variabel pupuk kandang memiliki tanda positif dan berpengaruh nyata terhadap produktivitas kopi arabika, yang berarti semakin banyak pupuk kandang yang digunakan dalam proses produksi maka produksi akan semakin meningkat. Sebagaimana diketahui bahwa pupuk kandang berfungsi untuk mengikat air tanah yang lebih besar sehingga pupuk yang terlarut masih tersedia dalam tanah, selain itu pupuk kandang juga dapat meningkatkan daya agregasi tanah, pori-pori tanah dan air tanah sehingga hara menjadi tersedia bagi tanaman dan dengan demikian akan memacu pertumbuhan dan produksi tanaman kopi arabika. Hal ini senada dengan pendapat Gupta (1999) dalam Tahir (2011) bahwa proses penguraian pupuk 
kandang oleh mikroba memerlukan energi yang bersumber dari hara tanah, oleh karenanya apabila pupuk kandang yang diaplikasikan dalam jumlah yang memadai akan meningkatkan aktivitas mikroba tanah sehingga efisiensi penyediaan unsur hara akan meningkat pula. Untuk itu dengan penambahan pupuk kandang pada pertanaman kopi akan memicu pertumbuhan, dengan sendirinya produksi juga akan meningkat.

Variabel tenaga kerja memiliki koefisien regresi positif dan berpengaruh nyata terhadap produktivitas kopi arabika. Hal ini berarti peningkatan jumlah tenaga kerja akan meningkatkan produksi. Berdasarkan kenyataan di lapangan, dalam kegiatan budidaya kopi arabika diperlukan tenaga kerja yang banyak untuk memaksimalkan kegiatan usahatani, utamanya pada saat panen agar hasil panen bisa optimal maka penggunaan tenaga kerja harus ditingkatkan.

Penambahan tenaga kerja akan dapat meningkatkan produksi kopi arabika dengan kontribusi pada kegiatan pemupukan dan panen buah kopi yang membutuhkan tenaga yang banyak agar tidak ada hasil yang terbuang karena terlambat dipanen. Upaya penambahan yang dapat dilakukan dapat berupa penambahan jam kerja maupun penambahan jumlah pekerja. Hal yang harus diperhatikan adalah upaya penambahan tenaga kerja harus diimbangi dengan penambahan kualitas dari sumber daya manusia agar lebih berpengaruh terhadap peningkatan produksi kopi arabika. Kurang maksimalnya penggunaan tenaga kerja disebabkan karena kurangnya penggunaan tenaga kerja upahan mengingat pada umumnya petani di lokasi penelitian memiliki lahan sendiri yang harus dikelola sendiri. Disamping itu upah tenaga kerja luar keluarga tergolong mahal utamanya pada saat panen raya sehingga petani berpikir perlu mengeluarkan dana lebih untuk biaya upah bila akan menggunakan tenaga kerja upahan yang lebih banyak.

\section{KESIMPULAN}

Berdasarkan hasil analisis data seperti yang telah diuraikan sebelumnya, maka dapat disimpulkan bahwa variabel independen secara bersamasama berpengaruh nyata terhadap produksi kopi arabika. Adapun faktor-faktor input yang berpengaruh terhadap produksi per luas lahan kopi arabika adalah pupuk Urea, pupuk ZA, herbisida, pupuk kandang dan tenaga kerja.

\section{DAFTAR PUSTAKA}

Coelli, T.J., D.S.P. Rao and G.E. Battese. 1998. An Introduction to Efficiency and Productivity Analysis. Kluwer-Nijhoff, Boston.

Debertin, D. L., 1986. Agricultural Production Economic. Second Edition. Mc. Graw Hill Inc. New York.

Dinas Perkebunan Sul-Sel, 2005. Laporan Tahunan, Pengembangan Kopi di Sulawesi Selatan. Dinas Perkebunan Provinsi Sulawesi Selatan, Sulawesi Selatan.

Dinas Perkebunan Enrekang, 2005. Laporan Tahunan, Pengembangan Kopi di Sulawesi Selatan. Dinas Perkebunan Propinsi Sulawesi Selatan, Sulawesi Selatan.

Dinas Pertanian dan Perkebunan Enrekang. 2011. Laporan (Angka Sementara 2011). Laporan Luas Areal dan Perkebunan Rakyat Kabupaten Enrekang, Sulawesi Selatan.

Hayami,Y., and V. W. Ruttan, 1985. Agriculture Development: An International Respective. The Jhon Hoppkins Press, Baltimore, London.

ICO, 2010. "Coffee: Botanical Aspects". International Coffee Organization. http:/ /www.ico.org/botanical.asp diakses 16 Mei 2010. 
Nicholson, W. 1998. Microeconomic Theory, Basic Principlesand Extentions. Seventh Edition. The Dryden Press, Fofth Worth.

Salazar, M., 2006. An Economic Analysis of Smallholder Coffee Production in Guatemala, Honduras, Nicaragua and Vietnam. Tesis. Purdue University. West Lafayette Indiana.
Tahir, A.G., 2011. Analisis Efisiensi Usahatani dan Risiko Produksi Kedelai di Sulawesi Selatan. Disertasi. Program Pasca Sarjana Fakultas Pertanian Universitas Gadjah Mada. Yogyakarta. (unpublished). 